\title{
Presentación del libro "Temas actuales de Derecho Internacional” en homenaje al Profesor Emérito Mario Ramírez Necochea ${ }^{1}$
}

\author{
Presentation of the book "Temas actuales de Derecho Internacional" in bonor of the \\ Emeritus Professor Mario Ramírez. Necochea
}

\author{
Marisol Peña \\ mpenat@uc.cl \\ Ministra del Tribunal Constitucional de Chile, Profesora de la Facultad de Derecho de la Pontificia \\ Universidad Católica de Chile, Master en estudios internacionales por la Universidad de Chile.
}

\section{Introducción}

Hoy nos encontramos en la Casa de Bello para homenajear a uno de esos grandes hombres que son los mejores testimonios de que las personas somos seres "trascendentes", pues independientemente de que creamos o no en una vida posterior a la terrena, esos seres especiales nos demuestran que las obras que realizamos en ésta, están llamadas a permanecer y a iluminar el futuro de las nuevas generaciones.

Éste es el caso del Profesor Emérito de la Universidad de Chile, Mario Ramírez Necochea, cuya labor académica ha motivado un merecido reconocimiento a través de la obra que hoy presentamos y que él mismo calificó como el más "hermoso regalo académico", según nos refiere el profesor Eduardo Picand Albónico en la presentación del libro.

1 Presentación efectuada en el acto de homenaje al Prof. Mario Ramírez Necochea realizado el jueves 9 de marzo del 2017 en el Aula Magna de la Facultad de Derecho de la Universidad de Chile, y que contó con la presencia del señor Rector de la Universidad, del Decano de la Facultad de Derecho, de una serie de autoridades gubernamentales y académicas, de familiares del Prof. Ramírez Necochea y de alumnos de la Facultad.

Número de página no utilizable para citar 
Desde luego, comienzo por agradecer a la Facultad de Derecho de la Universidad de Chile y, en particular, a su Vicedecana, profesora Maricruz Gómez de la Torre, por haberme distinguido con el encargo de la presentación de estos "Temas Actuales de Derecho Internacional", en presencia de un auditorio tan selecto como el que hoy nos acompaña. No tuve la suerte de conocer profundamente a "don Mario", pero después de haber leído este texto y los testimonios que en él se consignan, quisiera haber tenido tiempo de hacerlo.

Con todo, debo decir que las pocas veces que coincidimos en eventos académicos quedé impactada por su sencillez y claridad de ideas, a lo que mis propios padres -ex alumnos de esta Facultad- han agregado interesantes detalles de su vida universitaria que me confirman que hablamos de un hombre congruente con sus ideas y con una arraigada vocación académica.

\section{La personalidad del homenajeado}

Para abocarnos a presentar la obra mencionada, es de justicia referirnos, en primer término, a ciertos rasgos de la personalidad del homenajeado que son destacados en esta obra. Y qué mejor, que derivarlos de la voz autorizada de sus discípulos, como es el caso de los profesores Eduardo Picand y Jaime Gallegos.

El primero de ellos nos señala, en los agradecimientos iniciales, que don Mario fue "una persona transversalmente querida por toda la comunidad universitaria”, caracterizándose por su gran humanidad. He llegado a la conclusión que este rasgo de su carácter, unido, por cierto, al estudio sistemático de la realidad internacional, lo llevó a escribir su libro "Temas para un Derecho de la Humanidad", destacado especialmente por el profesor Mario Arnello en la presentación del homenajeado, como por la profesora Carola Canelo, quien toma este concepto para desarrollar una visión crítica de diversos temas de la realidad jurídica nacional.

Jaime Gallegos, por su parte, inicia su artículo de análisis de la reciente Ley Paraguaya de Derecho aplicable a los Contratos Internacionales con una semblanza del profesor Ramírez Necochea como formador de nuevas generaciones de académicos. Se refiere a la forma humilde en que compartía sus conocimientos con sus discípulos y al generoso impulso que les daba para proseguir su formación académica, de lo cual da cuenta la historia del propio autor de ese artículo. 
En fin, sus dotes de investigador permanente de los nuevos paradigmas y las propuestas que ellos le sugerían quedaron plasmadas en el vasto número de libros, artículos especializados y tesis que dirigió, muy bien sintetizados por Eduardo Picand.

Uno de los grandes atractivos de este libro está constituido por los diversos enfoques derivados de los artículos que en él se contienen. Pienso que este rasgo de la obra refleja otro aspecto de la personalidad del profesor Mario Ramírez Necochea referido a su actitud amplia y de respeto hacia las posiciones diversas, debidamente destacada por don Mario Arnello, y que, sin duda, unida a sus méritos académicos, justificó su permanencia -por largo tiempocomo Director del Departamento de Derecho Internacional de esta Facultad.

\section{Aspectos generales del libro}

La obra que hoy nos convoca representa una muy interesante muestra de lo que podríamos denominar el "estado de la cuestión" en materia de Derecho Internacional. Y no me refiero sólo al Derecho Internacional Privado - la disciplina que cultivaba don Mario- sino que también al Derecho Internacional Público, dado que temas propios de este último como la importancia creciente de los derechos humanos, las inmunidades jurisdiccionales de los Estados y sus bienes, la noción de "expulsión colectiva", como también la tesis del "margen de apreciación nacional" en cuanto criterio para enfrentar eventuales colisiones entre la normativa internacional y los ordenamientos jurídicos internos, son abordados en los artículos escritos por los profesores Leonel Pereznieto, Edmundo Vargas, Rita Lages y Gilda Cicci, respectivamente.

Asimismo, el artículo del profesor Hugo Llanos aborda los efectos del cambio climático en los derechos humanos justificando plenamente el desarrollo de esa nueva área del Derecho Internacional Público que corresponde al Derecho Internacional del Medio Ambiente.

Otra cuestión esencial del Derecho Internacional Público es abordada en el libro desde una perspectiva muy interesante. Me refiero al artículo de la profesora María Teresa Infante sobre el estudio iniciado por la Comisión de Derecho Internacional de las Naciones Unidas respecto de aquellos elementos que contribuyen a identificar la presencia de una costumbre internacional reconociendo cambios significativos desde las primeras sentencias recaídas en los casos Lotus y Plataforma Continental del Mar del Norte, sobre todo en orden a la identificación de la opinio iuris. Este artículo me ha sugerido, incluso, una metodología diferente para enseñar, en nuestros cursos, las fuentes del Derecho Internacional Público, pues, en lugar

Número de página no utilizable para citar 
de dar un tratamiento relativamente autónomo a aquéllas contenidas en los numerales 1) y 2) del artículo 38 del Estatuto de la Corte Internacional de Justicia, hoy parece imponerse la necesaria interacción entre los tratados y la costumbre internacional.

Por otra parte, considero que esta obra puede ser perfectamente citada para graficar diversos aspectos del proceso de globalización en que nos encontramos insertos. En efecto, diversos artículos que van dando cuenta de las nuevas regulaciones en materia de contratación internacional son un claro reflejo de la importancia de la lex mercatoria como rasgo característico de las relaciones que marcan esta era globalizada. En este punto, varias ponencias contenidas en esta obra destacan la importancia que sigue teniendo el principio de la autonomía de la voluntad, por ejemplo, para la determinación de la lex fori, aplicable tanto en lo que respecta a la elección del tribunal competente como a las reglas aplicables al procedimiento.

Paralelamente, la trascendencia que ha ido adquiriendo el arbitraje internacional, como medio de solución de controversias entre partes que se encuentran vinculadas por negocios que, muchas veces, se desarrollan en espacios virtuales, tiene un claro reflejo en esta obra a través de los artículos de los profesores Elina Mereminskaya, Ana Fernández, José Carlos Fernández y Gonzalo Stampa.

Al mismo tiempo, el impactante desarrollo de las tecnologías como de las redes que se han denominado "intermésticas" es considerado a propósito del artículo sobre la regulación de los contratos de consumo a través de Internet a partir del análisis de un interesante fallo del Tribunal de Grande Instance de París realizado por la profesora argentina Sara Feldstein de Cárdenas.

El libro también consigna aspectos que permiten entender las nuevas coordenadas que se están aplicando a los fenómenos migratorios, tan característicos de esta época y cuyo origen no sólo puede atribuirse a políticas determinadas como la de la libre circulación de personas en la Unión Europea, sino que a las verdaderas crisis humanitarias por las que estamos atravesando producto del avance de los movimientos terroristas y de la incapacidad de los Estados para contenerlos. Estas realidades han llevado, sin duda, a una revisión de las reglas aplicables hasta hoy en lo que concierne al estatuto de los refugiados, de lo que dan cuenta muy bien los artículos de las profesoras Ana María Moure y Rita Lages. Pienso que, sobre todo, este último, referido al concepto de "expulsión colectiva" en la jurisprudencia del Tribunal Europeo de Derechos Humanos irá cobrando creciente actualidad en la medida que el actual Presidente de los Estados Unidos concrete las medidas ya anunciadas respecto al trato frente a cierta categoría de extranjeros. 
Pero el libro que presentamos tiene aún una perspectiva más amplia, porque también aborda interesantes tópicos de la teoría de las relaciones internacionales aplicada a relaciones bilaterales específicas como ocurre con el artículo del profesor Eduardo Ortiz, que contiene una "Síntesis histórica de las Relaciones Internacionales de Estados Unidos y Chile 18101973”. Lo mismo sucede con la ponencia del profesor José Rodríguez Elizondo: “Apuntes para ser un buen vecino. Por una política renovada hacia Bolivia, incluido el 'Factor Peruano"'. En el primero se aprecia la visión realista de las relaciones internacionales, marcada por el factor estado céntrico y el predominio del interés nacional, anticipando, no obstante, los nuevos criterios que van a empezar a tallar después del término de la Segunda Guerra Mundial así como de la Guerra Fría que, y que seguramente darán origen a un estudio posterior del autor. El segundo es claramente un artículo propositivo, pues, a partir de las lecciones históricas que ha dejado la relación trilateral (Chile-Bolivia-Perú) y de la HV3 (en términos estratégicos), se destaca la importancia de contar con una diplomacia profesionalizada "capaz de tomar los riesgos manejables para alejar los riesgos mayores".

Simplemente, me atrevería a agregar que, paralelamente, parece importante el desarrollo de la teoría de las "crisis internacionales" que, a diferencia de lo que ocurre ante la inminencia de un conflicto bélico, pone el acento en la preparación del Estado, a través de todos sus campos de acción, para enfrentar debidamente un escenario más complejo.

Finalmente, quisiera llamar la atención sobre las sugerentes ideas derivadas de varios de los artículos de esta obra en orden a perfeccionar la normativa interna en diversos aspectos donde el Derecho Internacional Privado, en materia comparada, ha mostrado un desarrollo más acorde a los signos de los tiempos, como sugiere el profesor Pablo Cornejo en su artículo referido al Derecho Internacional Privado de las Sucesiones que analiza la experiencia de la Unión Europea.

De la mano con estas últimas reflexiones considero necesario seguir considerando la importancia del Derecho Comparado como modelo o parámetro de enfoque de problemas y conflictos jurídicos que nuestro Estado ya está enfrentando. En este sentido, la revisión de los curriculae de nuestras Facultades para incorporar esta asignatura, en forma independiente a las tradicionales, sigue siendo un interesante desafío. 


\section{Palabras finales}

La presentación de un libro como el que hoy nos ha reunido siempre conlleva un tremendo desafío, pues hay que vencer dos tipos de tentaciones: la primera es resumir el libro, de modo que, en lugar de incentivar la lectura, el público sienta que ya lo ha leído. Y, la segunda, es aprovechar la oportunidad de la presentación para exponer ideas propias que opaquen el aporte de los autores y, por cierto, el pensamiento del homenajeado.

En el día de hoy, he procurado -aunque con dudas sobre su éxito- un equilibrio entre ambos extremos y si no lo he logrado plenamente es porque la lectura de esta obra me ha dado muchas ideas para mis clases y para renovadas conversaciones con los colegas de nuestra disciplina.

Por ello pido excusas a los autores de los artículos y a la familia del profesor Mario Ramírez Necochea si no ha sido un intento apropiado a la envergadura de este acto. Sobre todo, me dirijo a aquellos autores cuyos nombres pude haber omitido en esta presentación, no porque sus artículos no sean interesantes, sino porque ellos se insertan en una línea conceptual o doctrinaria que intenté relevar en forma general.

Señoras y señores, estimados colegas: en este libro escriben ocho profesores extranjeros y quince académicos chilenos, fuera de aquellos que, como el señor Decano, intervienen en la presentación del mismo. Ello ya sería razón suficiente para recomendar entusiastamente su lectura. Pero, la obra habla por sí misma y sigue siendo "el más hermoso regalo académico" que un profesor de la talla de don Mario Ramírez Necochea pudo recibir de su alma mater.

Felicito, entusiastamente, a Eduardo Picand por esta merecida iniciativa, a la Facultad de Derecho de la Universidad de Chile porque se engalana con esta nueva producción académica, y a cada uno de los autores de los artículos que nos entusiasman por seguir profundizando en las complejidades del Derecho Internacional del siglo XXI. 